\title{
Lo urbano y los espacios vacíos en la Amazonia como elementos en la producción de cartografías nacionales de Colombia
}

\section{THE CONCEPT OF URBAN AND EMPTY SPACES IN THE AMAZON AS ELEMENTS TO PRODUCE NATIONAL MAPS OF COLOMBIA}

\author{
O URBANO E OS ESPAÇOS VAZIOS NA AMAZÔNIA COMO ELEMENTOS NA \\ PRODUÇÃO DE CARTOGRAFIAS NACIONAIS DA COLÔMBIA
}

\begin{abstract}
Jorge Mario Aponte-Motta ${ }^{1}$
Para citar este artículo: Aponte-Motta, J. M. (2019). Lo urbano y los espacios vacíos en la Amazonia como elementos en la producción de cartografías nacionales de Colombia. Perspectiva Geográfica, 24(2), 69-83.

doi: 10.19053/01233769.9895

Jorge Mario Aponte-Motta ${ }^{1}$
\end{abstract}

Recepción:

28 de mayo de 2019

Evaluación:

8 de agosto de 2019

Aprobación:

23 de septiembre de 2019

\section{Resumen}

Las representaciones que tradicionalmente tenemos de la Amazonia omiten o minimizan los fenómenos urbanos que han sido parte fundamental de su configuración territorial, dejándonos la imagen de "espacios vacíos", "incógnitos" o "salvajes", que encierran selvas exuberantes, ampliamente diversas en fauna y flora, pero que no tienen dueños o habitantes civilizados $\mathrm{y}$, por lo tanto, sus riquezas pueden ser aprovechadas por quienes describen el territorio. Sin embargo, esos mismos espacios se encuentran internamente demarcados por poblaciones que por lo menos en la representación cartográfica ponen en cuestión el discurso del vacío, lo cual evidencia que la construcción de dichos vacíos se encuentra enmarcada en disputas

1 Doctor en Geografía de la Universidad Autónoma de Madrid. Investigador posdoctoral del Grupo de Estudios Transfronterizos del Instituto Amazónico de Investigaciones Imani de la Universidad Nacional de Colombia, Sede Amazonia. jmapontem@unal.edu.co. . 
por el control territorial en las cuales borrar o no representar formas humanas de habitación, así como establecer enclaves urbanos, bien sea en la práctica o solo en la representación, resulta funcional para el ejercicio de apropiación territorial. En este sentido, como parte del inicio exploratorio de esta investigación, reflexionaré sobre el papel de la ciudad en la producción espacial amazónica y las formas como lo urbano ha sido representado en el marco de las disputas asociadas a la consolidación de los espacios territoriales Estado-nacionales en la Amazonia, enfatizando particularmente en los ejercicios simbólicos de representar a Colombia en la Amazonia. Para ello, trabajaremos a partir del análisis y la deconstrucción del mapa, siguiendo la propuesta metodológica de Bryan Harley (2005), e intentaremos comprender los sentidos y razones de la representación iconográfica de lo urbano en algunos mapas que incluyen la región amazónica a finales del siglo XIX.

Palabras clave: Amazonia, ciudades, cartografía, espacio vacio, iconografía, representación.

\section{Abstract}

Our traditional representations of the Amazon overlook or minimize urban phenomena that have been fundamental to its territorial configuration. This created an image of "empty," "unknown," or "wild" spaces that enclose lush jungles with a wide diversity of fauna and flora and no owners or civilized inhabitants, so their wealth can be exploited by those who describe the territory. Nonetheless, these same spaces are internally demarcated by populations that, at least in the cartographic representation, call into question the empty space discourse. This shows that the creation of these empty spaces is framed by disputes over territorial control in which erasing or not representing human inhabitants, as well as establishing urban settlements either in practice or in representation only, is functional for land grabbing. As part of the exploratory stage of this research, we reflect on the role of the city in Amazonian space production and how the concept of urban has been represented in the framework of disputes associated with the consolidation of national-state territorial spaces in the Amazon, emphasizing the symbolic practice of representing Colombia in the Amazon. For this, we employ map analysis and deconstruction, following Bryan Harley's methodological proposal, and attempt to 
understand the meanings of and reasons for urban iconographic representation in some maps that include the Amazon region at the end of the 19th century.

Keywords: Amazon, cities, cartography, empty space, iconography, representation.

\section{Resumo}

As representações que tradicionalmente temos da Amazônia omitem ou minimizam os fenômenos urbanos que têm sido parte fundamental de sua configuração territorial, deixando-nos a imagem de "espaços vazios", "incógnitos" ou "selvagens", que envolvem selvas luxuriantes, amplamente diversificadas na fauna e flora, mas que não possuem donos ou habitantes civilizados e, portanto, suas riquezas podem ser aproveitadas por quem descreve o território. No entanto, esses mesmos espaços encontram-se internamente demarcados internamente por populações que, pelo menos na representação cartográfica, põem em causa o discurso do vazio, o que mostra que a construção desses vazios se enquadra em disputas pelo controle territorial para apagar ou não representar formas humanas de habitação, bem como estabelecer enclaves urbanos, seja na prática ou somente na representação, ai é funcional para o exercício da apropriação territorial. Nesse sentido, como parte do início exploratório desta investigação, refletirei sobre o papel da cidade na produção espacial da Amazônia e as formas pelas quais o urbano tem sido representado no âmbito das disputas associadas à consolidação dos espaços territoriais Estado-nacionais na Amazônia, enfatizando particularmente os exercícios simbólicos de representar a Colômbia na Amazônia. Para isso, vamos trabalhar a partir da análise e a desconstrução do mapa, seguindo a proposta metodológica de Bryan Harley (2005), e tentaremos entender os sentidos e as razões da representação iconográfica do urbano em alguns mapas que incluem a região amazônica ao final do século XIX.

Palavras chaves: Amazônia, cidades, cartografia, espaço vazio, iconografia, representação. 


\section{Introducción}

La Amazonia suele verse como una región donde lo urbano es secundario. Las imágenes que tradicionalmente tenemos de dicha región omiten los fenómenos urbanos, destacando selvas exuberantes con características paradisiacas o infernales, ampliamente diversas en fauna y flora. Esa imagen no solo omite la ciudad como hecho geográfico e histórico presente en las formas como ha sido pensado y configurado el espacio regional, y en ese camino se ha estructurado el territorio nacional, sino que ha obligado a pensar a la región como un espacio subordinado frágil, dependiente, incapaz de adelantar estrategias endógenas de desarrollo en el marco de un proyecto incluyente de nación, así como efectivos proyectos de integración supranacional de carácter regional.

Pese a la anterior mirada, las formas urbanas han estado presentes de diversas formas en los procesos de configuración territorial de la región amazónica. Nada más al indicar el papel que tuvieron los fuertes militares y las misiones religiosas como lugares con contenido geopolítico y de concentración poblacional en el marco de las pugnas por el control colonial del territorio, podemos percibir su importancia en la producción del espacio amazónico (Corrêa, 1987; Goulard, 2012a; 2012b; Zárate, 2008; 2013), entendiendo lo urbano, por lo menos desde su concepción, como espacio hegemónico de dominación y omitiendo por lo tanto las diversas formas de habitación y asentamiento ya presentes en la región, y que no estaban vinculadas con las estrategias coloniales de dominio del territorio.

Por otra parte, las representaciones cartográficas han sido artefactos culturales (Díaz, Muñoz \&
Nieto, 2010, p. 9) centrales en la construcción de imágenes que definen políticamente paisajes con formas diversas de relieves, formas de asentamiento humano, caminos y áreas jerárquicamente organizadas que definen la concepción y la expresión de los contenedores territoriales de poder, los cuales cambian históricamente. Es decir, la cartografía, a través de su discurso iconográfico, ha ido narrando paisajes de los lugares que describe y al mismo tiempo los ha ido creando en su acto de presentación y traducción. Igualmente, mediante los límites diversos trazados en los mapas, la representación cartográfica ha definido áreas que circunscriben escenarios de poder que se transforman según las circunstancias históricas, sociales y políticas (Harley, 2005). En esta medida, la cartografía ha sido central en la construcción conceptual y práctica del espacio amazónico.

Esto quiere decir que la cartografía es una construcción con sentidos, que no es aséptica y está relacionada con intereses, imaginarios y formas de representar de los diversos agentes generadores del mapa, desde su concepción hasta su distribución. En este sentido, el mapa no revela el espacio que describe, sino la forma particular como los diversos agentes implicados en su realización y su difusión quieren que sea visto (Harley, 2005). Así, a través de una lectura de los mapas pueden hacerse visibles las concepciones - que incluyen los discursos sobre lo urbano- asociadas a las formas particulares de representar el espacio.

Teniendo en cuenta lo anterior, desde la segunda mitad del siglo XVIII las cartografías pasaron de representar la Amazonia como una región intensamente habitada a presentar una región vacía. Las primeras representaciones la reflejaban habitada por los bestiarios importados de las narrativas 
medievales (Pizarro, 2009; Ramírez, 2001). Posteriormente, se mostraba como intensamente habitada por los muchos pueblos nativos que iban a ser o estaban siendo reducidos a misiones. Finalmente, a finales del siglo XVIII se empezó a representar vacía, deshabitada. Los espacios ocupados por pueblos indígenas que "deambulaban" se volvieron áreas desocupadas, inhóspitas, desconocidas, inclusive "desérticas", aunque, eso sí, disputadas por los poderes imperial-coloniales que querían controlarla (Aponte Motta, 2017b).

Dicha expresión de los regímenes de representación que borra la dimensión habitada del espacio que se representa en los mapas evidencia un giro en la concepción geopolítica de la región, que necesitaba consolidar la idea del vacío, del desierto verde que nos persigue desde entonces en las formas de representación de la región amazónica y que ha sido central en las maneras como esta ha sido integrada de forma subordinada en la construcción y la narración de los territorios de los Estados nacionales con presencia en la Amazonia, lo cual instituye a dicha región como el revés o la cara oculta de la nación que, como contracara, sustenta la construcción de un "otro" interno que permite la consolidación de un imaginario nacional hegemónico (Serje, 2005).

Pese a que dicha construcción discursiva ha borrado la ciudad no solo como espacio habitado y con una particular materialidad física como urbs, sino como entorno cultural y político, ciudad como $\mathrm{ci}$ vitas y polis, lugar del desarrollo de la ciudadanía y del ejercicio de la política (Capel, 2003), que definirían en alguna medida un "territorio civilizado", curiosamente en los mapas no dejan de apa- recer representaciones de lugares emblemáticos, fuertes, puestos de misión o sitios que por una $u$ otra razón han resultado de interés en la representación cartográfica, pese a que las leyendas inscritas sobre áreas extensas del mapa destaquen la idea de espacios vacíos e inexplorados. Sin embargo, ¿cómo puede estar inexplorado un espacio que al mismo tiempo es marcado con poblaciones en las representaciones cartográficas?

Lo anterior pone de manifiesto que pese al discurso que vacía el espacio de poblaciones y habitantes, lo urbano tiene una importancia radical en la representación del espacio y su narración. Por lo tanto, pese a que el discurso hegemónico construyó una idea de la Amazonia como espacio vaciado de habitantes, este mismo discurso necesitó de la representación de algunas expresiones urbanas para sustentar su narrativa de dominio del espacio.

Lo anterior conduce a pensar que la representación de ciertas manifestaciones urbanas tiene gran importancia en el ejercicio narrativo de domino sobre una región, discurso que corre paralelo a la idea de una región deshabitada y puesta a disposición de quienes pretenden dominarla. Es decir, representar expresiones urbanas en medio de un espacio que se quiere argumentar que está vaciado de habitantes y, por tanto, disponible, hace parte de un discurso que revela otro nivel de formas del ejercicio de control o reivindicación del dominio espacial sobre una región específica. Por lo tanto, lo urbano como acto hegemónico, como marca, aparece para reivindicar el espacio de dominio, no para reconocer la condición habitada y, por lo tanto, con dueños. En una región como la Amazonia, lo urbano aparece para fortalecer las narrativas de dominio. 


\section{Agustín Codazzi, mapas del}

\section{Atlas de Venezuela de $1840 \mathrm{y}$} un mapa del Atlas de Colombia de Felipe Pérez y Manuel María Paz de 1899: un primer esfuerzo

\section{analítico}

Como primer ejercicio del sendero investigativo, quiero acudir al trabajo pionero de Agustín Codazzi, quien ayudó a construir el "cuerpo" de los Estados nacionales de Colombia y Venezuela. Unos cuerpos modernos mediados por el mapa como uno de los principales mecanismos de construcción de la imagen nacional (Anderson, 1993).

Codazzi desarrolló una intensa labor cartográfica, primero en Venezuela y después en la Nueva Granada, donde murió antes de terminar su trabajo, lo cual le impidió continuar hacia Perú, donde había sido contratado (Sánchez, 1998). Fue encargado en Venezuela de realizar una "completa cartografía del país", labor que requirió diez años desde que le fue encomendada en 1830. Su trabajo fue impreso en París en 1840, lugar donde obtuvo gran reconocimiento por parte de las sociedades científicas y geográficas - entonces gran centro académico, político y económico mundial— e incluso del ya veterano Alexander von Humboldt (Sánchez, 1998, p. 616).

Tal reconocimiento no era para menos. Su trabajo fue pionero en la cartografía moderna. Para 1885 se estimaba que solo al rededor de seis mil millas cuadradas, es decir, menos de la novena parte de la superficie del globo había sido sometida al levantamiento cartográfico o se encontraba en proceso (Brown, 1977, p. 280).
Lo anterior evidencia cómo las primeras cartografías nacionales americanas como la presentada por Codazzi cumplieron un doble papel en la producción del espacio nacional. Uno es externo, ya que se puede presentar el territorio a los otros Estados, por ello la legitimidad del Estado venezolano se adquiere al presentar su atlas en París, donde el cartógrafo es reconocido por las academias científicas, e interno, en la medida en que define - o por lo menos lo intenta- el espacio soberano del Estado, es decir, dónde sus acciones son soberanas, qué recursos están disponibles para la utilización o recaudo y, de forma importante, hasta dónde se extienden los Estados vecinos, lo cual dota a las cartografías nacionales de un papel preponderante en la definición de los límites políticos y se constituyen en la base sobre la cual definir o disputar dichos espacios mediante el emplazamiento de poblados y el trazado de líneas, que permiten mantener o sedimentar las disputas en el plano del espacio representado, lo cual hace de estos documentos elementos centrales en los procesos de definición de los espacios nacionales.

La obra de Codazzi, como lo reconoció la academia francesa, fue muy importante para el conocimiento de la geografía americana. Sin embargo, su trabajo no era ajeno a las tensiones políticas - de hecho, una de las principales preocupaciones que tenía Venezuela para contratarlo era definir las cartas de las provincias de Maracaibo y Mérida, vecinas de la Nueva Granada (Sánchez, 1998, p. 139), Estado del cual Venezuela se había separado al disolverse la llamada Gran Colombia-, como tampoco a los imaginarios sobre la región amazónica.

Un elemento de gran interés es que algunos imaginarios sobre la Amazonia alimentados desde tiempos coloniales y reforzados por la mirada de los 
viajeros científicos fueron inscritos en las apues- físico y político de la República de Venezuela elatas de representación de los territorios nacionales. borado por Codazzi y muestra el territorio "actual" Ejemplo de esto es el mapa "América histórica, de los países americanos (Figura 1).

física y política actual", que hace parte del Atlas

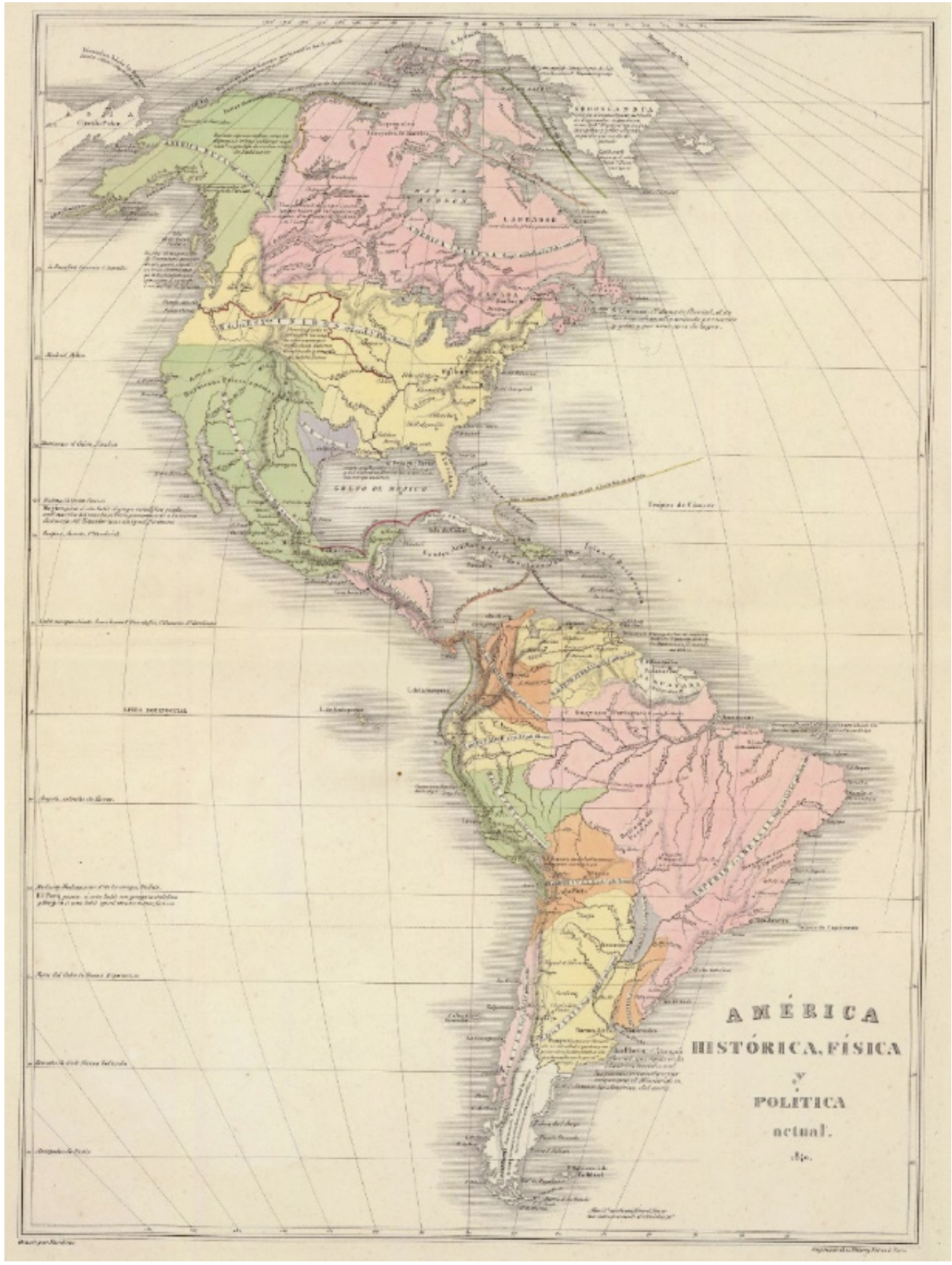

FIGURA 1.

“América histórica, física y política actual”: mapa elaborado por Agustín Codazzi en 1840. Fuente: Biblioteca Nacional de Colombia. 
En este mapa, en la parte en que se refiere a la Amazonia y la Orinoquia, habla de las Guyanas, anotando una división interna en tres partes (inglesa, holandesa y francesa) y una cuarta portuguesa, "apenas poblada", situación que es reforzada y extendida a toda la región con la inscripción: "País poco conocido, tribus indígenas y feroces en todas direcciones" (Figura 2).

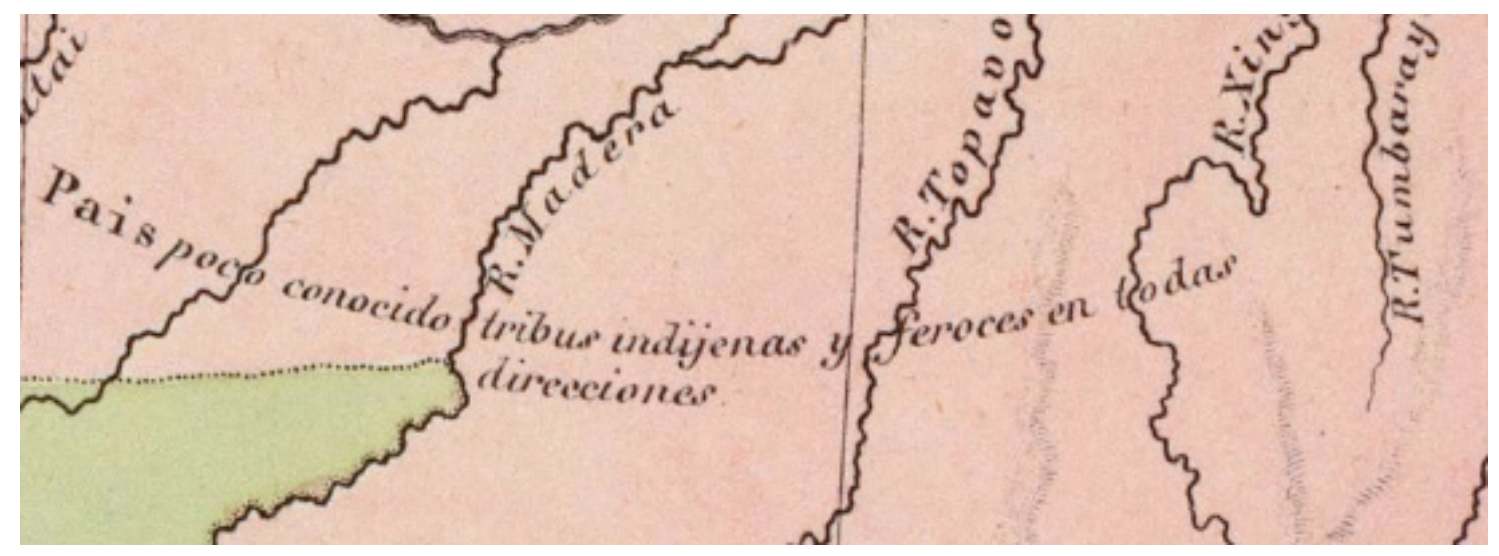

FIGURA 2.

"América histórica, física y política actual": detalle del mapa. Fuente: Biblioteca Nacional de Colombia.

La anterior inscripción destaca la insistencia en la narrativa cartográfica sobre el vacío cargado de desconocimiento, "país poco conocido" que es llenado por seres que sobresalen en su marginalidad y nomadismo como incapacidad de asentamiento que pueda generar entornos de aglomeración civilizados o ciudades: "Tribus indígenas feroces y en todas direcciones". Esto no solo refuerza la condición que construye "el salvaje" y, en esta medida, el incivilizado, sino que además destaca la condición de peligrosidad por su ferocidad, realza su "barbaridad" y su difícil localización.

Lo anterior es la condición primaria de los proyectos hegemónicos de producción del espacio que necesitan construir un "otro" sin lugar, nómada y además anclado en un estadio anterior o desvinculado del proceso civilizatorio, donde quien describe se asume como representante superior y legítimo. Dichas formas de construcción de un "otro", como condición necesaria para dominar el espacio en una nueva forma de producir el territorio, fue una estrategia discursiva ampliamente usada tanto por las misiones de los primeros tiempos coloniales como en la narrativa ilustrada del espacio esgrimida por los viajeros de los siglos XVIII y XIX (Aponte Motta, 2017a).

En este sentido, en el marco de la construcción de los espacios estado-nacionales, reapareció esta narrativa, lo cual implicó también marcar nuevos o renovados entornos urbanos en el marco de las condiciones de producción de la espacialidad de los confines amazónicos en clave de la construcción de los Estados nacionales ${ }^{2}$.

2 La inspiración para mirar el mapa de Codazzi la he tomado del trabajo de Sebastián Díaz (2008) y he agregado algunas impresiones y apreciaciones trabajadas previamente (Aponte Motta, 2013; 2017b). 
Lo anterior sugiere un elemento de suma importancia articulado directamente con el papel de lo urbano en la representación del espacio y que se puede vincular directamente con la representación de lo fronterizo. En representaciones pretéritas de la Amazonia, los cronistas, los misioneros y los primeros cartógrafos hablaban de grandes pueblos - por ejemplo, las ciudades de las Amazonas (presentes en la relación de G. de Carvajal), o la ciudad dorada de Manoa (en el relato W. Raleigh) — y sus mapas eran pródigos en ubicar poblaciones y áreas de influencia de diferentes "naciones" indígenas, funcionales a la construcción de los discursos que justificaban sus actividades en diversos momentos de las tensiones en la producción espacial.

Sin embargo, la ruptura de la representación ilustrada, de la cual beben los ejercicios de representación nacional que adelantan figuras como Codazzi, borra lo urbano de la Amazonia, tanto como referente prehispánico sujeto a dominación como de la propia espacialidad urbana generada en el ejercicio de dominación colonial. Por lo tanto, estos mapas, al no indicar poblaciones en la Amazonia, refuerzan el discurso de la región como vacía, inhabitada, un desierto donde solo deambulan o son ubicables los indígenas, lo cual marca el discurso de acción civilizadora sobre un espacio salvaje, a modernizar mediante una nueva forma de producción del espacio: los territorios estado-nacionales.

Estos discursos navegan entre la aparentemente inconclusa consolidación territorial colonial, las nuevas construcciones del saber que allanaron la complejidad de la región deshabitándola, unos imaginarios nacionales que siempre se pensaron andinos o litorales, y nuevos ejercicios de dominación del espacio que implicaron importación de población y llevaron "pueblos nobles" a "tierras salvajes". Estos habitantes civilizados habitarían nuevos o renovados entornos urbanos en frentes pioneros o en poblaciones fronterizas, las cuales, como antaño, se inscribieron muchas veces primero en el mapa antes que en el terreno.

Estas condiciones se hacen evidentes en diversas representaciones cartográficas de entonces, dado que la preocupación de la gran mayoría de los países andino-amazónicos se concentró más en la definición de los niveles administrativos internos que en la consolidación de un territorio nacional (Díaz, 2008, p. 31). Por ello, en gran parte los esfuerzos por integrar una región periférica como la Amazonia se vieron relegados a un segundo plano, confinándolas exclusivamente a una apropiación diplomática y, en alguna medida, cartográfica (Palacio, 2006, p. 88). De ahí la importancia que adquiere el espacio en el plano de la representación en la producción de las espacialidades estado-nacionales y, en este camino, la importancia que se evidencia en los ejercicios de representación de las fronteras y las poblaciones fronterizas en las cartografías nacionales.

No es gratuito, por tanto, que Codazzi, dentro del mismo Atlas de Venezuela, en la región donde anota la existencia de un país poco conocido habitado por salvajes feroces, indicara en otro mapa titulado "Carta de la República de Colombia dividida por departamentos" (Figura 3) poblaciones estratégicas como las de San Carlos, San Felipe y San José de Marabitanos (Figura 4), las cuales fueron entornos urbanos importantes en los esfuerzos de demarcación hispano-portugueses, así como áreas en disputa por el control territorial (Figura 4), sugiriendo así la existencia de territorios usurpados por brasilenses (sic) o por ingleses. 


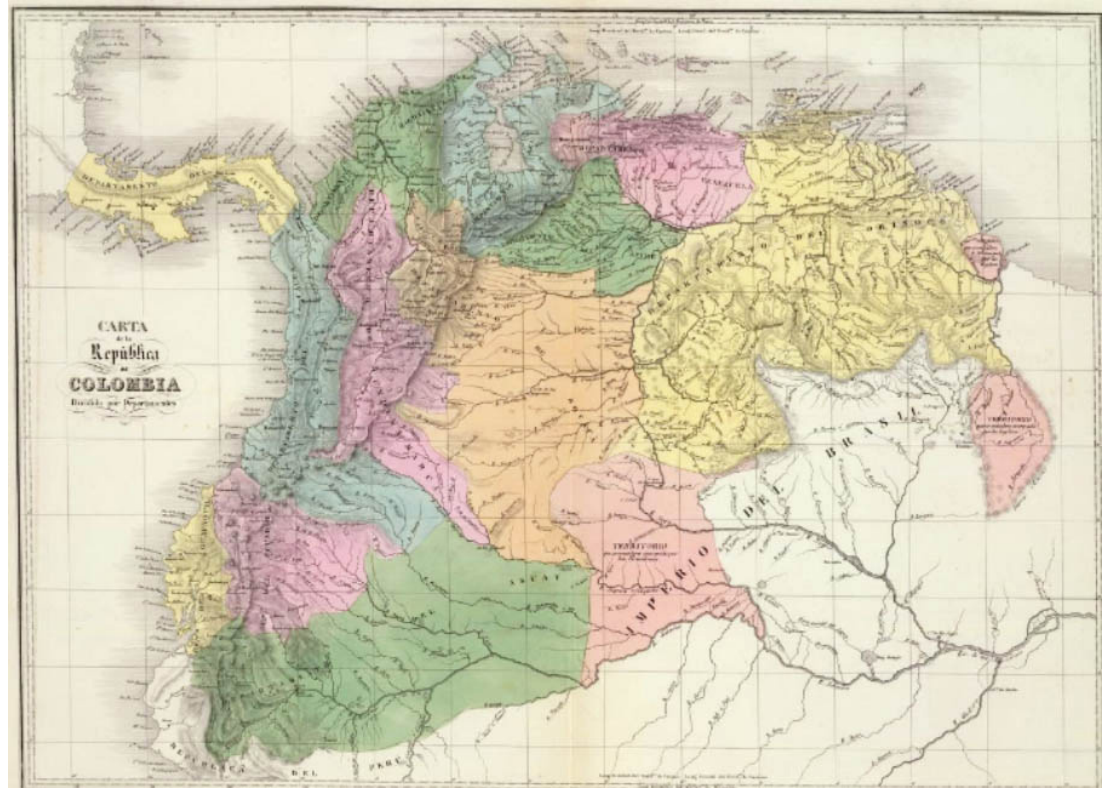

\section{FIGURA 3.}

"Carta de la República de

Colombia dividida por departamentos": mapa de Agustín Codazzi de 1840.

Fuente: Biblioteca Nacional de Colombia.

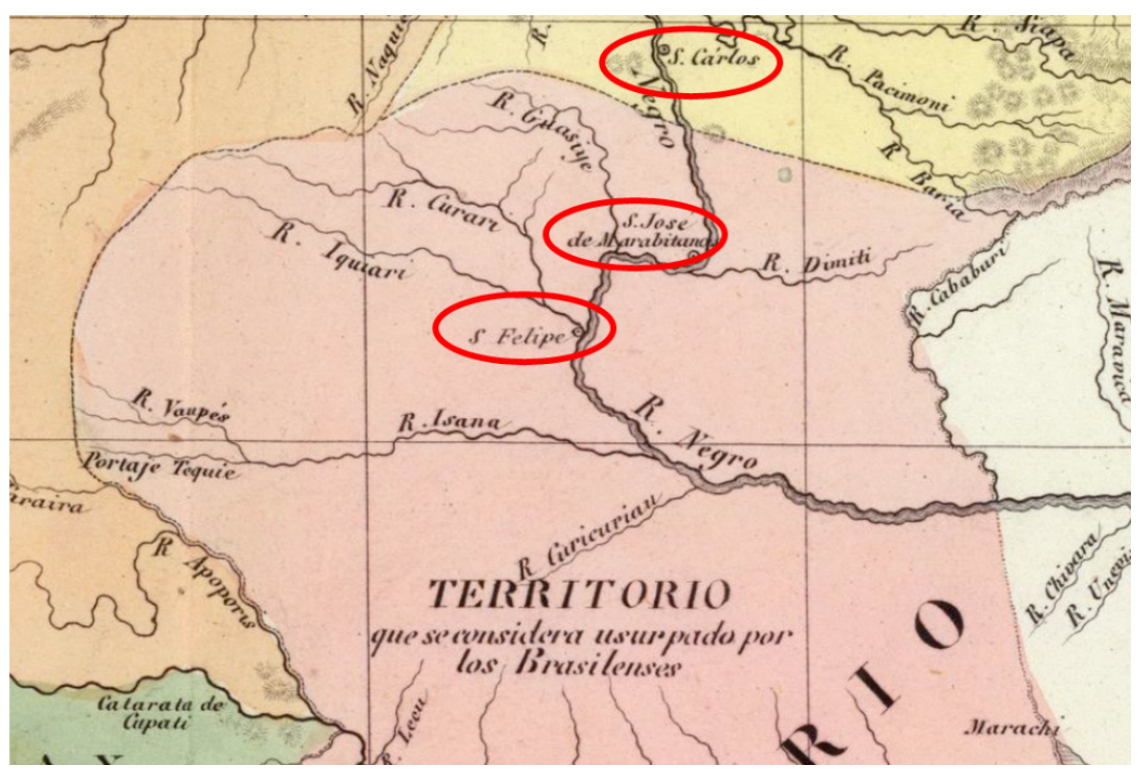

FIGURA 4.

Detalle de "Carta de la República de Colombia dividida por departamentos": los círculos rojos señalan las poblaciones estratégicas. Fuente: Biblioteca Nacional de Colombia.
Siguiendo con la figura emblemática de Codazzi, tras su regreso triunfante a Venezuela, después de la presentación en París del atlas, intentó establecer colonias agrícolas para favorecer la ocupación de agricultores europeos - esos pueblos nobles, europeos, en tierras salvajes, deshabitadas, sin ley y disponibles para ser aprovechadas - , lo cual fracasó rotundamente. Tras los conflictos internos en
Venezuela en 1847, el italiano terminó exiliado en la Nueva Granada, ad portas de iniciar una nueva aventura corográfica, la cual debería haber conducido a la realización de un atlas de igual o de mayor envergadura al realizado en Venezuela, que corrigiera y ayudara a definir, entre otras cosas, los límites con dicho país. 
La Comisión Corográfica iniciada en 1850 intentaría describir los diferentes elementos físicos, naturales, humanos y administrativos del territorio de la Nueva Granada (Sánchez, 1998, p. 240). Sin embargo, la empresa nunca fue terminada a causa de la prematura muerte de Codazzi en 1859.

Tras su muerte, los trabajos de la comisión fueron organizados y editados por varios investigadores que de una u otra forma estuvieron vinculados con dicha empresa científica. Entre estos, destaca el Atlas geográfico e histórico de la República de Colombia publicado por Felipe Pérez y Manuel María Paz en 1889. Dicho atlas, construido como imagen espacial y temporal aparentemente homogénea y sólida, como dispositivo gráfico que presentaba el territorio nacional, cumplió, como años atrás el Atlas de Venezuela, la doble función de presentación pública interna y externa de la imagen nacional, y en parte funcionó como discurso gráfico para contrarrestar las diferencias en la definición territorial entre Colombia y Venezuela (Díaz, Muñoz \& Nieto, 2013). Como parte de dicho discurso, Paz y Pérez mantuvieron una narración que involucró la delimitación y la utilización de poblaciones fundamentales en la construcción de la narrativa de la imagen del Estado nacional. Así, en el mapa "División política de Colombia en 1824", delinearon en rojo el perímetro del país, superponiéndose a las antiguas divisiones departamentales de la Gran Colombia que integraban a la Nueva Granada y Venezuela (Figura 5).

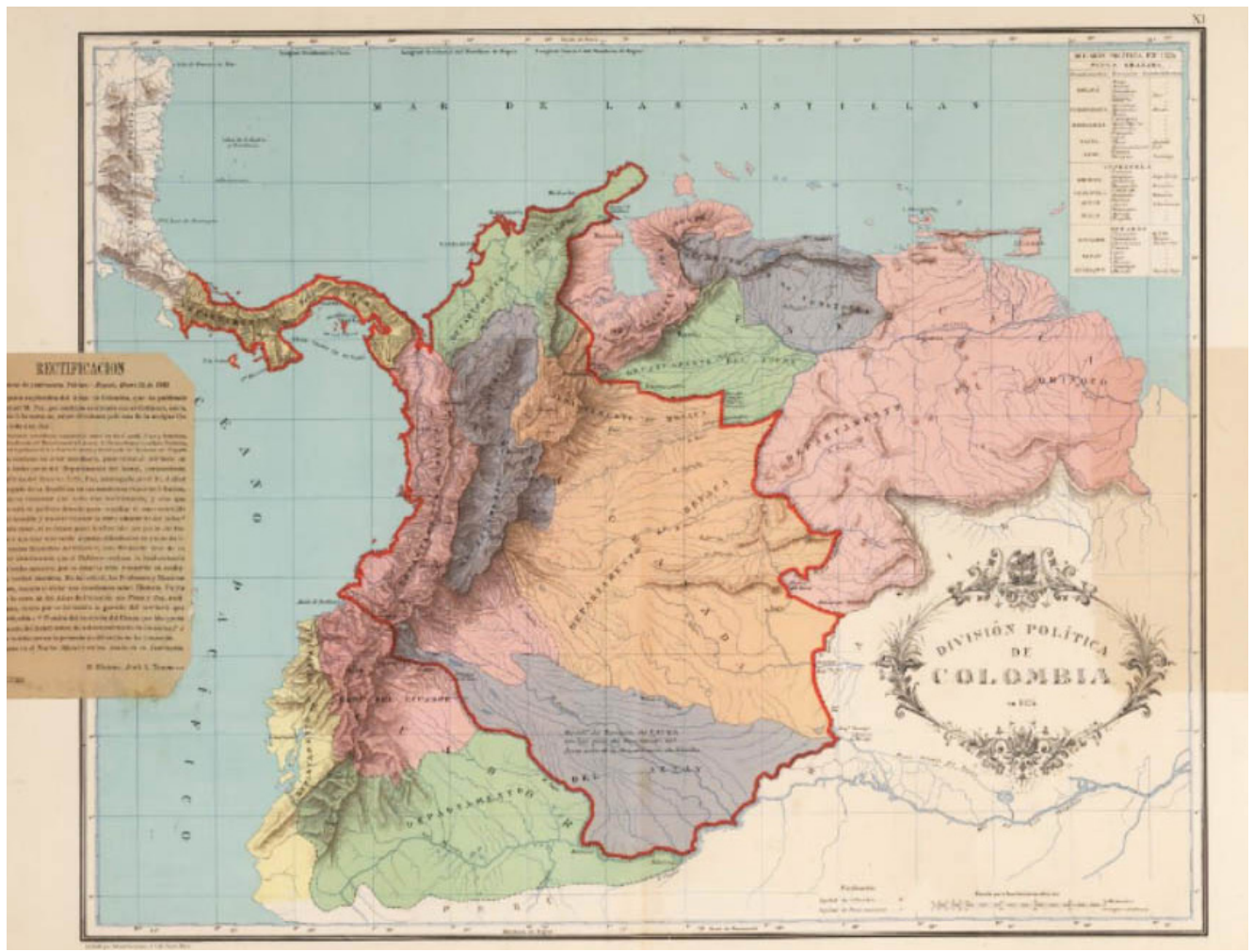

FIGURA 5.

“División política de Colombia en 1824”: mapa elaborado por Felipe Pérez y Manuel María Paz en 1889. Fuente: Biblioteca Nacional de Colombia. 
Este mapa, además de ser funcional a las disputas territoriales con Venezuela, adquiere especial relevancia en torno de la provincia de Azuay, en la frontera sur con Ecuador, dado que esta se encuentra atravesada por el límite. Nuevamente, tal como lo había hecho Codazzi al indicar "zonas usurpadas" en el Atlas de Venezuela, Paz y Pérez sugieren que la porción que queda dentro del pe- rímetro hizo parte de una división político-administrativa colombiana anterior (Figura 6) e indican como marca del límite la población de Tabatinga, fundamental en los intentos de delimitación hispano-portugueses dentro del departamento de Azuay, es decir dentro del territorio otrora español y no en territorio brasileño, y además fuera del perímetro territorial nacional colombiano.

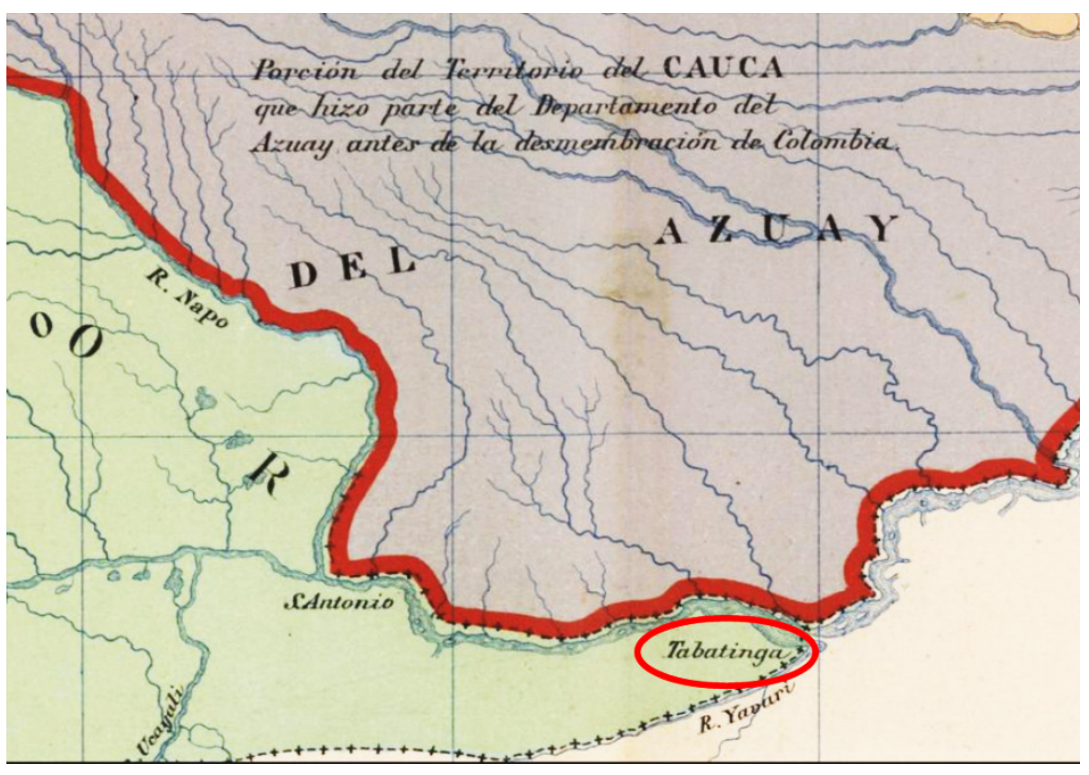

FIGURA 6.

Detalle del mapa “División política de Colombia en 1824": se resalta en rojo la ubicación de Tabatinga. Fuente: Biblioteca Nacional de Colombia.
Estos elementos ayudan a construir el discurso espacial, que es reiterativo en la construcción histórica del Atlas de Paz y Pérez respecto a la constante pérdida de territorio frente a los vecinos, dado que la porción que queda dentro del perímetro es una pequeña parte de lo que anteriormente era el país. Sin embargo, también tenía otra lectura, y es que la nota podría dar elementos de argumentación a Ecuador para asumir tales territorios como usurpados por Colombia. Ante tal amenaza, un año después de la publicación fue redactada una nota aclaratoria pidiendo hacer caso omiso de tal anotación.
Lo anterior, como mencionan Díaz, Muñoz y Nieto, manifiesta que tal rectificación no responde a errores del mapa de Paz y Pérez, sino a "diferentes visiones, discusiones y negociaciones de los límites territoriales y del ordenamiento político que tuvieron lugar en el proceso de construcción del territorio nacional" (Díaz et al., 2013, p. 168). Por lo tanto, en la construcción de ese espacio representado, los límites y las poblaciones fronterizas son elementos fundamentales del lenguaje cartográfico funcional a los proyectos de construcción de los cuerpos nacionales, donde lo urbano es una marca que ayuda a construir y legitimar la narrativa del dominio del territorio. 


\section{Conclusiones}

Tras una primera revisión de parte de la obra de Codazzi y del mapa de Pérez y Paz, se puede sugerir que esos espacios vacíos, zonas inexploradas, inexplotadas y habitadas por salvajes que es necesario dominar hacen parte central de las primeras formas de representación del espacio nacional, elemento que fue siempre acompañado por la representación de lo urbano como estrategia de legitimación de los dominios territoriales nacionales soportados sobre las historias de las disputas territoriales coloniales y, posteriormente, estado-nacionales.

Lo anterior sugiere que la frontera política delimitada en los ejercicios cartográficos, como elemento vivo en la pugna política de las representaciones, se vuelve un frente en la construcción de la frontera interna, para la cual son fundamentales los entornos urbanos, bien pintados en el mapa para servir de referente para trazar los límites, o como lugares de reducción de los pueblos habitantes del espacio simbólica y políticamente vaciado. De este modo, las visiones edénicas e infernales de la selva (Palacio, 2006) producidas por la mirada moderna-colonial son gestoras de los imaginarios que las élites criollas crearon sobre los habitantes y los territorios de las regiones "periféricas" o marginales de sus naciones. Dichos imaginarios estuvieron atados directamente a las formas de interactuar con regiones como la Amazonia, así como a las informaciones prácticas y conceptuales que proporcionaban las descripciones científicas vinculadas, como en los tiempos coloniales, a los esfuerzos por expandir la frontera de exploración y extraer lo que en la región se encuentre "disponible".

Por lo tanto, la producción del espacio geopolítico, tanto en la materialidad que subyuga a las "naciones indígenas" como en la representación que los borra o subordina a su salvajismo nómada, borra los referentes de habitación mientras intenta definir el contorno de los cuerpos nacionales. De este modo, la construcción científica del espacio no está desligada de su configuración geopolítica, como tampoco lo están los elementos particulares de los procesos de producción de los entornos urbanos amazónicos en el marco de las dinámicas espaciales del capitalismo; esto se expresaría de forma fehaciente, por ejemplo, en las dinámicas espaciales del modo de producción de la industria extractivista cauchera en la región.

La ciudad amazónica, de esta manera, hace parte de los proyectos geopolíticos —incluida la definición de espacios nacionales - y de la consolidación de proyectos económicos vinculados directamente a las formas modernas de producción. Sin embargo, pese a que el primer espacio se amojone con ciudades, la no-ciudad, el "nomadismo" y el carácter aparentemente inestable de sus pobladores que les impide "sedentarizarse" son el sustento para negar lo urbano de la Amazonia y, en esta medida, la capacidad de sus habitantes para establecer un diálogo horizontal en la construcción de la región, lo cual obliga, en esta narrativa, a imponer la ciudad como entorno hegemónico que volverá a los habitantes salvajes nacionales en el territorio delimitado de los Estados nacionales. 


\section{Referencias}

Anderson, B. (1993). Comunidades imaginadas. Reflexiones sobre el origen y la difusión del nacionalismo. México: Fondo de Cultura Económica.

Aponte Motta, J. (2013). El mapa y su logotipo en la construcción nacional de la Amazonia Colombiana. En I. Rojas (ed.), Historias locales en tiempos globales (pp. 175-202). Guadalajara, México: Universidad de Guadalajara.

Aponte Motta, J. (2017a). Estudiar la frontera desde una dimensión espacial. Reflexiones desde ciudades fronterizas de la Amazonia. En H. Padilla, A. Furlong, R. Netzahualcoyotzi \& J. Sandoval (eds.), Las fronteras: espacios estratégicos para la globalización. Puebla/Ciudad Juárez: Universidad Autónoma de Puebla/ Universidad Autónoma de Ciudad Juárez.

Aponte Motta, J. (2017b). Leticia y Tabatinga. Construcción de un espacio urbano fronterizo. Hacia una geohistoria urbana de la Amazonia. (Tesis doctoral). Universidad Autónoma de Madrid, España.

Brown, L. (1977). The Story of Maps. New York: Dover Publications, Inc.

Capel, H. (2003). A modo de introducción: los problemas de las ciudades. Urbs, civitas y polis. Mediterráneo Económico, 3, 9-24.

Codazzi, A. (1840). América histórica, física y política actual. [Mapa litografía; 51 x $65 \mathrm{~cm}$. En Atlas físico y político de la República de Venezuela dedicado por su autor, el Coronel de Ingenieros Agustín Codazzi al Congreso Constituyente de 1830. París/ Caracas: Thierry Freres. Disponible en David Rumsey Historical Map Collection http://www.davidrumsey.com/luna/servlet/s/9ax8w0 y en la Mapoteca Digital de la Biblioteca Nacional de Colombia http://bibliotecanacional.gov.co/es-co/ colecciones/biblioteca-digital/mapoteca/Documents/rg_23107.pdf.

Codazzi, A. (1840). Carta de la República de Colombia dividida por departamentos. [Mapa litografía; 43 x $60 \mathrm{~cm}$ ]. En Atlas físico y político de la República de Venezuela dedicado por su autor, el Coronel de Ingenieros Agustín Codazzi al Congreso Constituyente de 1830. París/Caracas: Thierry Freres. Disponible en David Rumsey Historical Map Collection http://www.davidrumsey.com/luna/servlet/s/x72752 y en la Biblioteca Nacional de Colombia http://bibliotecanacional.gov.co/es-co/ colecciones/biblioteca-digital/mapoteca/Documents/rg_23107.pdf.

Corrêa, R. (1987). A periodizaço da rede urbana da Amazônia. Revista Brasileira de Geografia, 3(49), 39-68.

Díaz, S. (2008). Contribuciones a la historia de la cartografía en Colombia. Una red de investigadores y un caso de estudio. (Trabajo de grado). Universidad Nacional de Colombia, Bogotá, Colombia.

Díaz, S. Muñoz, S. \& Nieto, M. (2010). Ensamblando la nación: cartografía y política en la historia de Colombia. Bogotá: Ediciones Uniandes. 
Díaz, S. Muñoz, S. \& Nieto, M. (2013). Desensamblando la nación. El caso del Atlas geográfico e histórico de Colombia de 1889. En O. Restrepo (ed.), Proyecto Ensamblado en Colombia. Vol. 1. Ensamblando Estados (pp. 143-178). Bogotá: Universidad Nacional de Colombia.

Goulard, J.-P. (2012a). El medio Amazonas a finales del siglo XVIII: un espacio insumiso. En C. Zárate (ed.), Espacios urbanos y sociedades transfronterizas en la Amazonia (pp. 45-67). Leticia: Universidad Nacional de Colombia, Sede Amazonia.

Goulard, J.-P. (2012b). El nor-oeste amazónico en 1776. Expediente sobre el cumplimiento de la real cédula dada en San Idelfonso, a 2 de septiembre de 1772. Leticia: Universidad Nacional de Colombia, Sede Amazonia.

Harley, B. (2005). La nueva naturaleza de los mapas (2a ed.). Mexico: FCE.

Palacio, G. (2006). Fiebre de tierra caliente. Una historia ambiental de Colombia 18501930. Bogotá, Colombia: ILSA, Universidad Nacional de Colombia-Sede Amazonia, Saber y Gestión Ambiental.

Paz, M. M. \& Pérez, F. (1889). División política de Colombia en 1824. [Mapa litografía; 48 × $60 \mathrm{~cm}$ ]. En Atlas geográfico e histórico de la República de Colombia (Antigua Nueva Granada): el cual comprende las repúblicas de Venezuela y Ecuador con arreglo a los trabajos geográficos del general de ingenieros Agustín Codazzi ejecutados en Venezuela y Nueva Granada. Construida la parte cartográfica por Manuel M. Paz, Miembro de la Sociedad de Geografía de París y redactado el texto explicativo por el doctor Felipe Pérez. Todo de orden del Gobierno Nacional de Colombia. París: A. Lahure. Disponible en David Rumsey Historical Map Collection http://www. davidrumsey.com/luna/servlet/s/4j1u3w y en la Mapoteca Digital de la Biblioteca Nacional de Colombia http://catalogoenlinea.bibliotecanacional.gov.co/client/ es_ES/search/asset/134317

Pizarro, A. (2009). Amazonía, el río tiene voces: imaginario y modernización. Santiago de Chile: Fondo de Cultura Económica.

Ramírez, M. del P. (2001). Construir una imagen. Visión europea del indígena americano. Sevilla, España: CSIC - Fundación El Monte.

Sánchez, E. (1998). Gobierno y geografía: Agustín Codazzi y la Comisión Corográfica de la Nueva Granada. Bogotá: Banco de la República-El Acora.

Serje, M. (2005). El revŭs de la nación. Territorios salvajes, fronteras y tierras de nadie. Bogotá: Ediciones Uniandes-CESO.

Zárate, C. (2008). Silvícolas, siringueros y agentes estatales: el surgimiento de una sociedad transfronteriza en la Amazonía de Brasil, Perú y Colombia 1880-1932. Recuperado de http://www.bdigital.unal.edu.co/3225/.

Zárate, C. (2013). Pueblos indígenas y expediciones de límites en la Amazonia, siglos XVIII-XX. En F. Correa Rubio, J.-P. Chaumeil \& R. Pineda Camacho (eds.), El aliento de la memoria: antropología e historia en la Amazonia andina. Bogotá, D. C.: Instituto Francés de Estudios Andinos. 